\title{
A ESTRUTURA DOS COMPOSTOS ORGÂNICOS EM LIVROS DIDÁTICOS DE NÍVEL SUPERIOR: análise sob a perspectiva de Bachelard
}

\author{
Jaime da Costa Cedran' \\ Ourides Santin Filho²
}

\section{RESUMO}

O presente trabalho tem por objetivo analisar a sequência apresentada por alguns livros didáticos de química orgânica, ao abordar as estruturas carbônicas e seu arranjo espacial, e discuti-las sob a ótica da epistemologia de Gaston Bachelard. Os livros foram escolhidos por serem adotados nas disciplinas introdutórias de Química Orgânica em algumas das principais universidades brasileiras. Os resultados mostram que todos os livros se iniciam com a mesma abordagem o tema de estrutura e propriedades dos compostos orgânicos, partindo das características eletrônicas do átomo de carbono e das possibilidades de sua hibridação, para depois apresentarem conceitos mais simples, obtidos a partir de dados experimentais. Tal abordagem caracteriza uma inversão do ponto de vista histórico e também do ponto de vista epistemológico, tomando como referencial a sequência de escolas filosóficas propostas por Bachelard.

Palavras-chave: Química Orgânica. Análise de Livros Didáticos. Bachelard.

\section{THE ORGANIC COMPOUNDS STRUCTURE IN HIGHER EDUCATION TEXTSBOOKS:}

\section{analysis under bachelard's perspective}

\begin{abstract}
This study aimed to investigate the sequence presented by some organic chemistry textbooks when addressing the carbonic structures and their spatial arrangement. The books were selected for being adopted in introductory courses in Organic Chemistry in major Brazilian universities. The results show that all textbooks begin similarly with regard to structure and properties of organic compounds, starting from the electronic characteristics of the carbon atom and the possibilities for its hybridization, and then present the simplest concepts obtained starting from experimental data. Such an approach features a reversal of the historical point of view and also from an epistemological point of view, taking as a reference the sequence of philosophical schools proposed by Bachelard.
\end{abstract}

\footnotetext{
I Doutorado em Educação para a Ciência e a Matemática (UEM). Professor da Universidade Tecnológica Federal do Paraná - campus Medianeira. Orcid iD: https://orcid.org/0000-00030757-1212. E-mail: jaimecedran@utfpr.edu.br

2 Doutorado em Química (USP). Professor da Universidade Estadual de Maringá. Orcid iD: https://orcid.org/0000-0001-5128-5390 E-mail: osantin@vem.br
} 
Keywords: Organic Chemistry. Textbook Analysis. Bachelard.

\section{LA ESTRUCTURA DE LOS COMPUESTOS ORGÁNICOS EN LIBROS DIDÁCTICOS DE NIVEL SUPERIOR: análisis en la perspectiva de bachelard}

\section{RESUMEN}

El presente trabajo tiene por objetivo analizar la secuencia presentada por algunos libros didácticos de química orgánica, al abordar las estructuras carbónicas y su arreglo espacial, y discutirlas en la óptica de la epistemología de Gastón Bachelard. Los libros fueron elegidos por ser adoptados en las disciplinas introductorias de Química Orgánica en algunas de las principales universidades brasileñas. Los resultados muestran que todos los libros se inician con el mismo enfoque el tema de estructura y propiedades de los compuestos orgánicos, partiendo de las características electrónicas del átomo de carbono y de las posibilidades de su hibridación, para después presentar conceptos más simples, obtenidos a partir de datos experimentales. Tal enfoque caracteriza una inversión desde el punto de vista histórico y también desde el punto de vista epistemológico, tomando como referencial la secuencia de escuelas filosóficas propuestas por Bachelard.

Palabras clave: Química Orgánica. Análisis de Libros Didácticos. Bachelard.

\section{INTRODUÇÃO}

A Química Orgânica (QO) é uma das principais subáreas da química. Seu escopo é muito amplo, contemplando desde a síntese de novos materiais ao estudo de compostos isolados de organismos vivos, entre outros. Como subárea da Química, a QO se consolidou durante o século XIX, ao se transformar de ciência dedicada ao estudo de compostos derivados de organismos vivos, para o estudo dos compostos que apresentam como elemento químico principal o Carbono, designação também já em desuso.

Desde então, a QO tornou-se uma das disciplinas fundamentais nos cursos de formação de profissionais de Química. Sua abordagem se inicia em geral com os aspectos estruturais das moléculas dos compostos orgânicos, sua nomenclatura, arranjo espacial, e a relação do arranjo com as propriedades físicas das substâncias, para que então se discutam as peculiaridades das reações químicas que envolvem os compostos orgânicos.

As teorias modernas sobre a maneira como átomos estão conectados nos compostos orgânicos se baseiam em modelos formais, alicerçados na 
Química Quântica. Além da dificuldade de se lidar com a complexidade das teorias necessárias para compreender orbitais atômicos e seus desdobramentos, alguns trabalhos (MULLINS, 2008; ANDERSON; BODNER, 2008; O'DWYER, 2012) mostram que a compreensão do arranjo espacial dos compostos orgânicos também não é trivial. Os alunos universitários nem sempre conseguem compreender a relação entre uma propriedade observada macroscopicamente e a estrutura submicroscópica de um composto químico. Os trabalhos citados, de uma forma ou de outra, apontam que a compreensão da disposição espacial dos átomos e/ou a relação existente entre a estrutura dos compostos e suas propriedades são dificuldades apresentadas pelos alunos investigados em diferentes contextos.

Para auxiliá-los a superar as dificuldades apresentadas, o professor possui algumas ferramentas que podem ajudar nesse processo, sendo o livro didático, o instrumento utilizado com maior frequência, inclusive no ensino superior. Conforme afirma Campanário (2001)

Os livros são importantes ferramentas no processo educacional, podendo até ser considerados o principal eixo para a condução do referido processo, e acaba por influenciar tanto as estratégias desenvolvidas pelo professor como a forma de estudo dos alunos (CAMPANÁRIO, 2001, p. 351).

Cada livro apresenta, de maneira implícita ou explícita, concepções a respeito da ciência e do conhecimento científico (FERNANDES; PORTO, 2012, p. 420), influenciando a visão de seus leitores a respeito da ciência que aborda. Se essa concepção tiver natureza excessivamente cientificista, ela irá contribuir, mesmo que indiretamente, para o fortalecimento dessa concepção nos acadêmicos, mesmo que em sua aparência, sugiram abordar conteúdos de forma neutra.

Dada a importância dos livros didáticos, bem como as dificuldades que os alunos apresentam especialmente em Química Orgânica, o presente trabalho pretende avaliar qual é a abordagem apresentada pelos livros sobre a estrutura dos compostos orgânicos, um dos temas iniciais da disciplina e que serve como base para a compreensão dos demais assuntos. 
Ao considerar a construção histórica desse conceito, ocorrida durante o século XIX, constata-se que ela partiu da determinação empírica das fórmulas dos compostos e foi se sistematizando até a proposição de teorias que buscavam compreender como os átomos estavam conectados. É importante salientar que a proposta que contempla o arranjo espacial foi feita cerca de duas décadas antes da descoberta do elétron e 50 anos antes das modernas teorias de ligações químicas.

Embora a construção histórica tenha sido ampla e complexa, descreveremos cronologicamente alguns trabalhos pontuais que contribuíram para o entendimento da noção de estrutura dos compostos orgânicos, a fim de facilitar o entendimento de nossa análise.

Em 1860, Lovis Pasteur conseguiu explicar satisfatoriamente porque alguns compostos com composição idêntica têm comportamento diferente, quando sobre eles incide um feixe de luz plano polarizada. Isso foi possível porque Pasteur foi capaz de separar manualmente cristais de derivados do ácido tartárico aparentemente idênticos, mas que ele notou serem imagens especulares uns dos outros. (PASTEUR, 1901).

Em 1876, independentemente, Jacobus van'† Hoff e Joseph Le Bel apresentaram a proposta da geometria tetraédrica para compostos nos quais o átomo de carbono estivesse conectado a quatro outros átomos (ou grupo de átomos). Essa proposta, além de explicar como os átomos estavam arranjados espacialmente, conseguia convergir a explicação experimental de Pasteur com os pressupostos teóricos derivados dos postulados sobre os compostos de carbono, desenvolvidos por Kekulé em 1861 (KEKULÉ, 1861).

Com a ideia do arranjo espacial para as moléculas já incorporada pela comunidade científica, foi apenas nas primeiras décadas do século XX, após a descoberta do elétron em 1897, que os cientistas começaram a pensar em modelos formais de ligações químicas.

Pelos três trabalhos citados se evidencia 0 incremento da complexidade no decorrer da história, que parte do trabalho fundamentalmente empírico de Pasteur, passa pela proposta estrutural de van'† Hoff e Le Bel, e chega finalmente à proposta das ligações químicas 
formais, já no início do século XX. Alguns autores apresentam esse contexto histórico de forma mais ampla e fundamentada (CAMEL, 2010; CEDRAN, 2015), mas, para o contexto desse trabalho, esta breve descrição é suficiente para compreender a análise aqui considerada.

Neste trabalho, analisamos a sequência de conteúdos apresentada pelos livros didáticos, sob a ótica da epistemologia de Gaston Bachelard. Ele defende que o conhecimento pode ser compreendido a partir de diferentes escolas filosóficas, numa sequência crescente de complexidade, a saber: realismo - empirismo - racionalismo (BACHELARD, 1990). Tal sequência está associada ao processo de desenvolvimento histórico do conceito. Ao defendê-la, o autor argumenta que

[...] não vemos como se poderiam dispor de forma diferente as filosofias que tomamos por base. As numerosas tentativas de modificação que levamos a cabo falharam todas a partir do momento em que as referimos a um conhecimento particular. [...] depois de muitos exames particulares, adotamos para os conhecimentos objetivos particulares a ordem realismo - empirismo - racionalismo. Esta ordem é genética. Um conhecimento particular pode expor-se numa filosofia particular; mas não pode fundar-se numa filosofia única; o seu progresso implica aspectos filosóficos variados (BACHELARD, 1991, p. 29).

A sequência de escolas filosóficas para certo conceito científico faz parte do que Bachelard denominou de "perfil epistemológico". O autor considera que a noção de um determinado conceito presente na mente de um sujeito não pode ser completamente compreendida a partir de um único sistema epistemológico. O autor defende que, para um determinado conceito, um sujeito atribui diferentes significados em diferentes contextos, definido num perfil com diferentes regiões.

Os diferentes problemas do pensamento científico deveriam, pois receber diferentes coeficientes filosóficos. Em particular, o grau de realismo e de racionalismo não seria o mesmo para todas as noções[...]. Em linhas gerais, o devir de um pensamento científico corresponderia a uma normalização, à transformação da forma realista em forma racionalista. Esta transformação nunca é total. Nem todas as noções estão no mesmo estádio das suas transformações metafísicas (BACHELARD, 1991, p. 9). 
Nessa obra, Bachelard apresenta seu próprio perfil epistemológico para o conceito de massa, ilustrado pela Figura 1.

FIGURA 1 - O perfil epistemológico de Bachelard para a noção de massa.

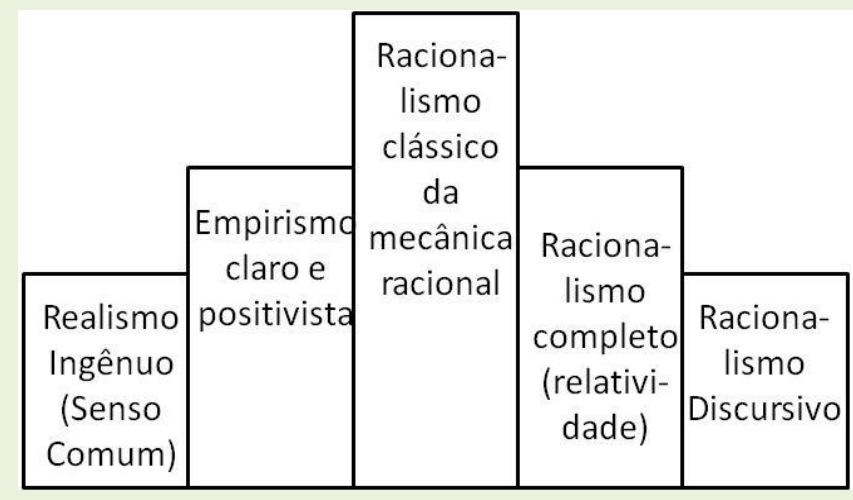

Fonte: Bachelard (1991, p.41)

Notemos que o conceito de massa pode ser compreendido de diversas formas, desde o realismo ingênuo até o que ele chama de racionalismo discursivo. Cada zona do perfil epistemológico caracteriza o conceito em estudo - massa, nesse exemplo - segundo as concepções das respectivas escolas filosóficas. Embora no espectro apresentado pelo autor existam cinco zonas diferentes para o conceito de massa (Figura 1), Bachelard afirma que, particularmente, utiliza com maior frequência o perfil racionalista clássico, já que a magnitude de cada um deles é inerente a cada indivíduo. Além disso, nem todos os indivíduos fazem uso de todos os perfis existentes para certo conceito em questão. Utilizando o exemplo do conceito de massa, é possível afirmar que existem indivíduos que não possuem em seu espectro especialmente o último perfil apresentado. Esse perfil só será desenvolvido se o indivíduo tiver contato com as teorias físicas pertinentes ao mesmo.

Com base na obra de Bachelard, apresentamos uma proposta para o perfil epistemológico do conceito de estrutura de compostos químicos (CEDRAN, 2015), que servirá de base para a análise dos livros didáticos.

Primeiramente é importante salientar que, tratando-se de estrutura de uma molécula, não é possível concebê-la apenas com observações da natureza, ou por meio de dados empíricos. O conceito de estrutura molecular remete necessariamente a uma noção racional. Por isso, para 
propor as zonas do perfil epistemológico para esse conceito, imaginamos qual(is) seria(m) o(s) conceito(s) precursor(es) para a noção de estrutura, para então identificarmos quais seriam as características das duas primeiras zonas do perfil (realista e empirista) para o conceito em questão.

Propomos que nas zonas inicias devemos tratar do conceito de substância, pois acreditamos que, se racionalizado, ele pode levar ao conceito de estrutura molecular. Temos clareza que outros destinos seriam possíveis através da racionalização desse conceito, como por exemplo: a estrutura íntima da matéria (partículas subatômicas); ligações químicas; propriedades físico-químicas da matéria; entre outros, que fogem ao escopo do presente trabalho.

Baseado nos perfis propostos por Bachelard (1991) para massa e energia, e nos demais trabalhos presentes na literatura (SOUZA, 2008; SOUZA FILHO, 2009; SOUZA et al, 2009; BUSCATTI JUNIOR, 2014; ANDRADE et al, 2017), caracterizamos a seguir as zonas do perfil epistemológico para a noção de estrutura dos compostos, especialmente, compostos orgânicos.

Zona do Realismo Ingênuo

Com relação à primeira zona do perfil epistemológico, Bachelard afirma que a visão realista é inata; ela não é ensinada, mas intrínseca ao indivíduo; ela sempre traz o conhecimento ao plano do imediato das coisas.

Nesta zona do perfil epistemológico, entendemos que as substâncias são diferenciadas pelos seus aspectos físicos, como por exemplo: a cor, a aparência, a textura, o cheiro, entre outros. Sob este ponto de vista, substâncias diferentes têm aspectos diferentes. Por exemplo: a água e a terra são substâncias diferentes, assim como o ouro e a prata e, porque não, um cubo de gelo seria uma substância diferente da água contida num copo. Poderíamos elencar aqui uma série de outros exemplos para ilustrar nossa tese, que acabariam se tornando redundantes.

Fundamentamos nossa proposta mais uma vez em Bachelard (1991), quando este afirma que, para o conceito de massa, uma criança com o perfil realista ingênuo, escolhe uma fruta pelo seu tamanho, sem fazer outro juízo da fruta. Podemos traçar um paralelo e afirmar que a diferenciação 
entre as substâncias é feita pela distinção dos aspectos físicos apresentados pelas mesmas, pois esse é o aspecto real inerente a tais substâncias.

Nesse contexto, uma substância é uma porção de matéria que apresenta propriedades que thes são características. Porém tais propriedades, para um indivíduo que apresenta esse perfil majoritariamente, são apreendidas apenas pela observação, sem qualquer intervenção empírica.

O realista ingênuo classifica a substância pela cor ou aspecto que enxerga; pela textura que sente; pelo cheiro que percebe. Reafirmando o que foi apresentado no início deste tópico, a visão realista é inata, intrínseca, derivada de uma análise imediata.

Zona do Empirismo Claro e Positivista.

$\mathrm{Na}$ segunda zona do perfil epistemológico, a zona empirista, o conceito é formulado com base em experiências simples e corresponde ao emprego da objetividade tátil ou instrumental, com uso de instrumentos de medidas, mas que ainda não consta de relações racionais (SOUZA FILHO, 2009).

Como exemplo desse perfil podemos citar: as primeiras classificações de substâncias químicas, como a distinção entre compostos ácidos e básicos, através do uso de indicadores no século XVII; o isolamento de uma série de novos "ares", durante o século XVIII, pelos chamados químicos pneumaticistas, sendo considerado um novo gás aquele que apresentasse propriedades diferentes dos gases já conhecidos; a reatividade dos compostos frente a um determinado ácido ou base; entre outros.

Os exemplos acima podem ser compreendidos do ponto de vista empirista pois, com análises relativamente simples, é possível chegar às conclusões descritas, sem estabelecer relações racionais entre os fatos. Por exemplo, afirma-se que uma substância é ácida porque altera a cor de certo indicador ácido-base, porém, não se discute as relações existentes entre o conjunto de substâncias classificadas como ácidas.

Assim, na zona empirista entende-se que as características de certo composto estão contidas no próprio composto, levando ao que Bachelard 
chama de substancialismo: "a ideia substancialista quase sempre é ilustrada por uma simples continência. É preciso que algo contenha que a qualidade profunda esteja contida" (BACHELARD, 1996 p. 123).

Para concluir a discussão desta zona, entendemos que, segundo o ponto de vista empirista, é possível classificar as substâncias por meio de suas propriedades físicas e/ou químicas conhecidas experimentalmente, mas não é possível prever a existência de novos fenômenos ou substâncias. Além disso, pela visão empirista não é possível compreender que as características das substâncias são derivadas das interações entre partículas que a formam, ou delas com outras, mas se considera que tais propriedades são inerentes às substâncias.

\section{Zona do Racionalismo Clássico da Mecânica Racional}

Na terceira zona, a racionalista clássica. é possivel associar a estrutura dos compostos químicos com as características físico-químicas dos mesmos. Historicamente, podemos associar a ascensão do racionalismo para o conceito de estrutura molecular a três fatos ocorridos durante o século XIX, conforme cita Mortimer (1997): A proposição da Teoria Atômica de Dalton; a ideia de Isomerismo, de Berzelius, e o desenvolvimento das primeiras propostas de estruturas químicas, até a proposição de carbono tetraédrico por van'† Hoff e Le Bell independentemente.

No que diz respeito à estrutura dos compostos orgânicos, foco desse trabalho, o modelo atômico já era usado como premissa para as tentativas de se fundar uma teoria capaz de se adequar aos dados experimentais, vinculada a uma proposta estrutural, ocorridas durante o século XIX. Nesse contexto Bachelard afirma que:

A necessidade de se estabelecer relação entre os dados empíricos e os dados teóricos fez Auguste Laurent, em meados do século XIX, afirmar que uma ciência química que se limite à mera descrição dos fenômenos não está cumprindo seu papel. Laurent quer que os fatos confirmem as ideias, mas é preciso que as ideias imediatamente façam prever novos fatos (BACHELARD, 2006 p. 54).

Em conclusão ao pensamento de Laurent, Bachelard afirma que "é preciso voltar ao laboratório e encontrar um intermediário entre os resultados 
da análise química e as propriedades das substâncias, ou seja, é preciso encontrar a significação fenomenal correspondente à composição." (BACHELARD, 2009, p 55).

Ao refletirmos sobre o intermediário citado, acreditamos que seja necessária alguma representação estrutural, pois é só por meio dessa representação que é possível estabelecer a relação entre o os resultados da análise química e as propriedades das substâncias. Por isso, o aspecto racional no que diz respeito ao conceito de estrutura dos compostos orgânicos só emerge com o estabelecimento da relação entre a estrutura e propriedades dos compostos citados.

Saliente-se que, embora aspectos racionais já estivessem inseridos nas primeiras discussões referentes às substâncias, como na determinação das fórmulas mínimas por meio da análise química, a noção de estrutura seria a "significação fenomenal" necessária para que fosse possível compreender a relação entre a fórmula dos compostos químicos e suas propriedades, ou seja, a relação entre os dados empíricos e uma proposta teórica que os sustentem e abram a possibilidade de previsão de novos fatos empíricos.

Assim, ao analisarmos a construção histórica das ideias acerca da estrutura dos compostos orgânicos, nos deparamos com algumas propostas apresentadas durante o século XIX que tentavam atrelar os dados empíricos conhecidos com uma teoria que fosse capaz de prever novos fenômenos. Dentre essas propostas podemos citar a Teoria Dualista de Berzelius, a Teoria dos Núcleos de Laurent, a Teoria dos Tipos de Dumas, e as noções de valência e tetratomicidade do carbono propostas por Kekulé.

A construção destas propostas teve necessariamente que estabelecer relação entre estrutura e propriedade dos compostos. Tal relação é um dos principais aspectos (ou o principal) para o desenvolvimento e compreensão das estruturas dos compostos orgânicos, pois, para que cada uma das teorias fosse proposta foi necessário que cada cientista tivesse conhecimento das propriedades físicas e químicas dos compostos e com essas informações teve de adequar sua proposta aos dados empíricos. 
A partir dessa reflexão racional, foi possível conceber suas estruturas como entidades espacialmente arranjadas e, além disso, entender a relação entre estrutura e propriedade físicas e químicas, fatores fundamentais para a compreensão de fenômenos químicos, especialmente vinculados à Química Orgânica. Ressalvamos, porém, que o racionalista clássico considera as estruturas como sendo absolutas e imutáveis; características mecanicistas inerentes à essa zona.

Zona do Racionalismo Completo

Essa zona é instaurada por conta da necessidade de uma nova filosofia racionalista, capaz de contemplar os novos fenômenos e teorias que apareceram na virada do século XIX para o século XX, em especial a Relatividade e a Teoria Quântica. A esse novo racionalismo Bachelard chamou de racionalismo completo.

Em relação à estrutura de compostos orgânicos, o racionalismo completo aparece por conta da descoberta do elétron, no fim do século XIX, e o nascimento da Mecânica Quântica, no início do século XX, eliminando o determinismo característico do racionalismo anterior. Exemplo disso é a impossibilidade de se conceber a estrutura atômica e, por consequência a estrutura molecular, de maneira estática. A explicação dos fenômenos atômico-moleculares então se matematiza, sendo propostas equações para interpretar o comportamento dessas entidades. Surgem os conceitos de orbitais atômicos e moleculares, que são interpretados com caráter estatístico.

Bachelard discute a nova teoria capaz de explicar a proposta do carbono tetravalente de Kekulé, colocando-a num outro patamar epistemológico:

[...] não se pode deixar de reconhecer que a teoria das funções tetraédricas do átomo de carbono tem um valor epistemológico maior que a teoria estereoquímica do carbono quadrivalente de Kekulé. Para ser mais preciso na avaliação dos valores epistemológicos, é necessário dizer que a mecânica ondulatória funda o modelo de Kekulé [...] A mecânica ondulatória faz-nos compreender verdadeiramente a organização tetraédrica de toda a química do carbono (BACHELARD, 1990, p. 172). 
Portanto, sob essa nova perspectiva, as estruturas dos compostos químicos passam a ser compreendidas por meio de novas teorias que contemplam a existência destes orbitais atômicos, orbitais moleculares, orbitais híbridos, e as propriedades físicas e químicas passam a ser compreendidas como derivadas das interações eletrônicas intra e intermoleculares.

Dessa maneira concluímos a descrição das zonas do perfil epistemológico para o conceito de estrutura dos compostos orgânicos. Vale comentar, por fim, que Bachelard afirma que em cada ciência ou, mais especificamente, em cada conceito, é possível existir diferença em relação ao número de zonas do perfil epistemológico. Segundo o autor, isso ocorre pois nem todos os conceitos estão no mesmo patamar, isto é, enquanto alguns deles já não possuem vestígios do realismo ingênuo, em outros o racionalismo quase nem existe (BACHELARD, 1991, p. 45). O autor ainda afirma que novas zonas do perfil epistemológico podem ser criadas, caso seja necessária uma nova filosofia para a compreensão de um conceito em estudo, porém Bachelard enfatiza que à medida que se "caminha" pelas zonas do perfil epistemológico, o caráter racional deve ser cada vez mais aprofundado em detrimento do aspecto realista.

Com base no desenvolvimento histórico e na obra de Bachelard, analisou-se a sequência apresentada por livros introdutórios às disciplinas iniciais de Química Orgânica na abordagem do conceito de estrutura dos compostos orgânicos. A análise visa identificar quais são os conhecimentos mínimos necessários, segundo cada livro, para que um estudante compreenda $\bigcirc$ assunto. Destacamos que $\bigcirc$ diálogo com $\circ$ referencial escolhido, a saber, o perfil epistemológico sugerido por Gaston Bachelard, será feito ao final da análise de todas as obras.

\section{METODOLOGIA}

Os livros foram escolhidos após consulta às referências bibliográficas das ementas de disciplinas de Química Orgânica (ou similares), para o curso 
de graduação em Química das seguintes universidades brasileiras: Universidade do Estado de Santa Catarina (UDESC), Universidade Estadual de Maringá (UEM), Universidade Federal Fluminense (UFF), Universidade Federal de Minas Gerais (UFMG), Universidade Federal de Pernambuco (UFPE), Universidade Federal de Santa Catarina (UFSC), Universidade de Brasília (UnB), Universidade Estadual Paulista "Júlio de Mesquita Filho" (UNESP), Universidade Estadual de Campinas (UNICAMP), Universidade de São Paulo (USP) e Universidade Tecnológica Federal do Paraná (UTFPR). Foram selecionadas as quatro obras mais citadas nas ementas. Trata-se então de uma análise documental, e não se fixou em alguns trechos específicos das obras, mas na sequência dos conceitos trazida para apresentar a noção de estrutura dos compostos orgânicos, que foi comparada com a sua gênese cronológica histórica.

\section{RESULTADOS}

Livros didáticos costumam conter somente as teorias vigentes necessárias para justificar os temas abordados na obra. Nesse sentido, não se espera que as obras atuais apresentem teorias que já foram abandonadas. Dessa forma, foi analisada qual foi a sequência de conceitos escolhida por cada autor para culminar na noção de estrutura dos compostos orgânicos.

As análises dos quatro livros são desenvolvidas abaixo. Descrevemos como os conceitos são apresentados em cada um deles, seguidos de uma breve discussão.

LIVRO 1: ALLINGER, N. L.; CAVA, M. P.; JONGH, D. C.; JOHNSON, C. R.; LEBEL, N. A.; STEVENS, C. L. Química Orgânica.2a Edição. Rio de Janeiro: Ed. LTC, 1976.

O livro de Allinger está organizado em 37 capítulos, agrupados em três partes. A análise se concentrou no segundo e no sexto capítulos, intitulados Teoria Estrutural e Estereoquímica, respectivamente.

O segundo capítulo é divido em cinco subitens. O primeiro traz um breve e superficial histórico, no qual os autores apresentam algumas análises 
químicas desenvolvidas no final do século XVII e início do XVIII. A segunda seção, intitulada Análises Químicas e Formas Moleculares, não faz qualquer comentário a respeito das "formas" dos compostos orgânicos, embora esse termo conste no título da seção.

$\mathrm{Na}$ seção seguinte, os autores apresentam brevemente A Teoria Estrutural de Kekulé (subitem 2.3). O texto começa com o problema da isomeria e citam como exemplo o fato de a fórmula $\mathrm{C}_{5} \mathrm{H}_{12} \mathrm{O}$ poder representar 14 compostos, com propriedades físicas diferentes. Segundo eles

\begin{abstract}
A importância de entender como os átomos se ligam [...] para formar moléculas já era compreendida pelos cientistas nos começos do século XIX, mas os químicos do tempo não tinham como resolver o problema. A solução foi produzida independentemente por Kekulé e Couper, em 1858. Estes cientistas postularam que o carbono teria a mesma valência 4 em moléculas orgânicas [...] que têm nas substâncias simples (ALLINGER, et al, 1976, p. 12).
\end{abstract}

O autor aborda superficialmente a questão dos isômeros do $\mathrm{C}_{5} \mathrm{H}_{12} \mathrm{O}$ e afirma que maiores discussões serão feitas posteriormente.

Na quarta seção do capítulo são introduzidas as Ligações Covalentes, que se inicia com a proposta de Lewis e Kossel. Em seguida, é apresentada a teoria do orbital molecular, com fundamentação na teoria quântica.

No último subitem do capítulo, os autores apresentam a Estrutura do Metano, em que discutem sua estrutura tetraédrica, proposta por van'† Hoff e Le Bel em 1874, e explicam:

\begin{abstract}
Estudos realizados com muitos metanos substituídos mostram, invariavelmente, que o número total de isômeros é coerente com uma estrutura de tetraedro regular para o metano, eliminando assim todas as geometrias possíveis [...] O porquê de o metano possuir essa estrutura, e não outras aparentemente plausíveis, só foi compreendido com o desenvolvimento da teoria quanto-mecânica, sendo até então aceita como um fato experimental (ALLINGER, et al, 1976, p. 18).
\end{abstract}

Após esse breve excerto sobre a proposta do carbono tetraédrico, os autores voltam mais uma vez à discussão de aspectos quânticos, tratando da necessidade de se formar orbitais híbridos para que se compreenda a estrutura do metano, encerrando assim o capítulo. 
Pelo resumo exposto, nota-se que a ênfase do capítulo está em aspectos quânticos, apresentando em momentos pontuais em que se estabeleceram relações entre os experimentos e as estruturas dos compostos orgânicos.

Chama a atenção, ainda no fragmento acima, a afirmação de que a estrutura só foi "compreendida" com o desenvolvimento da teoria-quantomecânica. Tal afirmação se caracteriza como epistemologicamente incorreta, pois deposita na teoria um cunho de verdade inquestionável que, uma vez conhecida, vai explicar definitivamente a natureza, e não como um modelo falível que teve que se adequar às evidências experimentais.

O capítulo 6, intitulado Estereoquímica, está dividido em 12 seções, e a sequência dos conceitos trazidos pelos autores segue a seguinte ordem: discussão sobre atividade ótica, exemplificando o funcionamento de um polarímetro; na sequência, define-se enantiômeros e misturas racêmicas, apresentando diversas projeções, com ênfase nas projeções de Fischer para representação de compostos com atividade ótica. No decorrer do capítulo, aprofundam-se questões relativas ao entendimento dos diversos tipos de isômeros e suas nomenclaturas específicas. Chama a atenção que apenas na décima seção se faz uma breve citação do trabalho de Pasteur. Seu trabalho é anterior à proposta do carbono tetraédrico por van't Hoff e Le Bel, e foi a partir daquele que se tornou possível propor a geometria tetraédrica para os compostos de carbono, base para toda a discussão apresentada no capítulo. Fica assim explícita a inversão do ponto de vista histórico na abordagem apresentada pelos autores.

Conclui-se que a abordagem dos autores do livro Allinger et al. (1976) apresenta inversão histórica em relação ao conceito de estruturas de compostos orgânicos, enfatizando inicialmente seus aspectos quânticos, para só posteriormente apresentar os dados experimentais que subsidiaram as formulações das primeiras teorias para o conceito em estudo.

LIVRO 2: BRUICE, P. Y. Química Orgânica.4a Edição. São Paulo: Ed. Pearson, 2011. 
O livro está dividido em 14 capítulos agrupados em três partes. A análise se limitará ao capítulo 1 (Estrutura eletrônica e ligação - ácidos e bases) e ao capítulo 5 (Estereoquímica).

O primeiro capítulo se inicia com uma introdução histórica. São três parágrafos, que resumem todo o início da Química Orgânica, nos quais são abordadas a diferenciação feita por Berzelius entre compostos orgânicos e inorgânicos e a síntese da ureia, realizada por Whöler.

Após o contexto histórico, a autora aborda algumas questões sobre a importância da Química Orgânica, até iniciar a explanação sobre a estrutura do átomo.

No primeiro subitem do capítulo l, é apresentada a estrutura do átomo começando pela sua descrição moderna. Novamente, o aspecto quântico é privilegiado, com menções a equações de onda e orbitais atômicos.

Depois dos átomos, percorre-se o mesmo caminho para as ligações químicas, passando pelas estruturas de Lewis, até chegar ao tópico Ligação em metano e etano: ligação simples. Mais uma vez, privilegia-se o aspecto quântico. Discute-se os orbitais presentes no átomo de carbono e a hibridização necessária para explicar a estrutura da molécula de metano. As ligações duplas e triplas são apresentadas dando ênfase aos orbitais atômicos envolvidos nas ligações.

No capítulo introdutório, em nenhum momento a autora faz relações da determinação das propriedades estruturais dos compostos orgânicos com os dados experimentais, ela simplesmente pressupõe que o leitor tenha conhecimento suficiente para compreender como as moléculas orgânicas estão espacialmente arranjadas, partindo do modelo quântico.

No capítulo 5, Estereoquímica, a autora, primeiro define os tipos de isomeria existentes, em seguida apresenta o que são carbonos quirais e estereocentros; após, são apresentadas projeções de Fischer e a nomenclatura de enantiômeros, para só então trazer exemplos baseados em dados experimentais, com a apresentação do polarímetro. A obra cita os trabalhos de Biot e van'† Hoff e Le Bel com o seguinte parágrafo: 
(Biot) percebeu que algumas substâncias giravam o plano de polarização (da luz) no sentido horário e outras no sentido antihorário, enquanto outras não alteravam o plano de polarização. Previu que a habilidade de girar o plano de polarização era atributo de alguma assimetria nas moléculas. Van't Hoff e Le Bel determinaram mais tarde que a assimetria molecular estava associada a substâncias que continham um ou mais carbonos assimétricos. (BRUICE, 2011 , p. 190).

Essa é a única citação ao trabalho de van’t Hoff. O trabalho de Pasteur aparece apenas no final do capítulo, ao se abordar resolução enantiomérica, complementando uma inversão histórica trazida pelo livro.

Enfatizamos que essa inversão histórica gera uma inversão epistemológica, pois modelos mais recentes apresentam um grau de complexidade maior que modelos antigos. Assim, ao invés de iniciar o assunto partindo de resultados experimentais, e apontar a necessidade de se estabelecer uma teoria baseada nestes resultados para a compreensão dos fatos observados, o que se apresenta é a teoria vigente, dando a impressão que o modelo está pronto e acabado e que os fatos são consequência dos modelos teóricos adotados e não o inverso.

Pela análise, notou-se que a autora apresenta conceitos quânticos no início da abordagem para depois apresentar dados empíricos que subsidiam a teoria. Conclui-se, portanto, que a obra também apresenta inversão histórica com relação as estruturas dos compostos orgânicos.

LIVRO 3: SOLOMOS, G.; FRYHLE, C. Química Orgânica. Vol. 1. $7^{a}$ Edição. Rio de Janeiro: Ed. LTC, 2000.

O terceiro livro analisado está organizado em 15 capítulos, dos quais foram analisados o primeiro, Ligação e Estrutura Molecular, e o quinto, Estereoquímica. O primeiro capítulo está divido em 20 seções, das quais as duas primeiras trazem um preâmbulo sobre moléculas orgânicas presentes na origem do Universo e, em seguida, o contexto histórico é apresentado, com alguma discussão da Teoria da Força Vital e a contraposição a ela causada pela síntese da ureia, executada por Whöler, sem maiores aprofundamentos. 
Na terceira seção, A teoria estrutural da Química Orgânica, os autores escrevem:

Entre 1858 e 1861, August Kekulé, Archibald Scott Couper e Alexander M. Butlerov, trabalhando independentemente, implantaram a base de uma das teorias mais fundamentais na química: a teoria estrutural. Duas premissas centrais são fundamentais:

1. Os átomos nos compostos orgânicos podem formar um número fixo de ligações utilizando seus elétrons do nível mais externo (valência). O carbono é tetravalente, isto é, os átomos de carbono têm quatro elétrons de valência e podem formar quatro ligações. $O$ oxigênio é divalente, e o hidrogênio e (geralmente) os halogênios são monovalentes.

2. Um átomo de carbono pode utilizar um ou mais de seus elétrons de valência para formar ligações com outros átomos de carbono. (SOLOMONS; FRYHLE, 2009, p. 3)

Nessa citação notam-se fortes contradições de cunho histórico. Primeiro, embora parte dos químicos da segunda metade do século XIX fossem atomistas, a noção de átomo ainda não estava completamente fundamentada; além disso, ainda havia alguma confusão acerca da nomenclatura das possíveis partículas existentes, de tal modo que os termos átomos e moléculas eram usados indiscriminadamente, possuindo significados diferentes para cientistas diferentes. Mas o principal problema da citação acima é a referência ao elétron. Ele aparece três vezes, sendo utilizado como argumento para justificar a teoria estrutural proposta pelos três químicos citados. No entanto, a ideia da existência de uma partícula carregada negativamente pertencente ao átomo só veio à tona nos últimos anos do século XIX, com o trabalho de J. J. Thomson, quase 40 anos após a publicação da teoria estrutural de Kekulé, Couper e Butlerov.

Especificamente nesta citação, a mistura de fatos historicamente isolados favorece uma visão de ciência que se desenvolve de maneira linear, sem percalços, que vem ao longo do tempo acumulando conhecimentos até chegar ao modelo atual e o autor, além de cometer erro histórico, inverte o percurso mais lógico, do ponto de vista bachelardiano, para a compreensão do conceito em analise, partindo de um aspecto mais complexo em direção a um aspecto mais simples. Nesse mesmo contexto os autores pontuam: 
Vemos que um carbono com hibridização $\mathrm{sp}^{3}$ fornece uma estrutura tetraédrica para o metano, e uma com quatro ligações $\mathrm{C}-\mathrm{H}$ equivalentes (SOLOMONS; FRYHLE, 2009 p. 23).

Segundo a citação, é a hibridização $\mathrm{sp}^{3} \mathrm{do}$ carbono que the vai "fornecer uma estrutura tetraédrica", isto é, a geometria seria consequência do tipo de hibridização apresentado. De fato, não é isso que ocorre, mas a hibridização é $\mathrm{sp}^{3}$ é uma justificativa teórica para uma geometria tetraédrica existente e já estabelecida empiricamente. Nota-se aqui que, mais uma vez, há uma abordagem invertida e epistemologicamente equivocada do percurso de construção dos conceitos.

Já no capítulo 5, os autores apresentam uma abordagem interessante da forma como van't Hoff e Le Bel propuseram a geometria tetraédrica para o carbono, na forma de exercício, conforme abaixo:

Mostre como uma estrutura quadrática plana para os compostos de carbono pode ser eliminada da consideração examinando-se $\mathrm{CH} 2 \mathrm{Cl} 2$ e $\mathrm{CH} 2 \mathrm{BrCl}$ como exemplos de metanos dissubstituídos. (a) Quantos isômeros seriam possíveis em cada caso se o carbono tivesse uma estrutura quadrática plana? (b) Quantos isômeros são possíveis em cada caso se o carbono é tetraédrico? (SOLOMONS; FRYHLE, 2009, P 183)

O exercício continua com exemplos de metanos trissubstituídos. A proposta é interessante e é baseada no trabalho original de van't Hoff, no qual se lê:

Quando as quatro afinidades do átomo de carbono são satisfeitas por quatro grupos univalentes, diferentes entre si, dois e não mais que dois diferentes tetraedros são obtidos, um que é imagem refletida do outro, eles não podem se sobrepor; isto é, nós temos que lidar com duas fórmulas estruturais isomérica no espaço (VAN'T HOFF,1874, p. 446, tradução nossa).

Embora a abordagem seja pertinente, ela é apresentada depois que conceitos mais complexos (como o termo enantiômero) já tivessem sido introduzidos, e de suas características já terem sido discutidas pelo autor. Teria sido mais conveniente apresentar tal exercício como problematização inicial para introduzir a discussão sobre a geometria dos compostos orgânicos. 
Seguindo a mesma linha, o trabalho de Pasteur só é apresentado quase ao final do capítulo, quando se discute separação enantiomérica. Mais uma vez, a abordagem não segue a sequência de construção histórica do conceito, pois foi o trabalho empírico de Pasteur que forneceu subsídios para o trabalho de van't Hoff e Le Bel que, por sua vez, iniciaram o desenvolvimento de estudos em estereoquímica. O caminho que o livro traça é o inverso, assemelhando-se às duas obras já analisadas.

A abordagem feita pelos autores também se inicia partindo de questões que envolvem conceitos quânticos para noções mais simples, caracterizando uma inversão que pode dificultar o entendimento do conceito por parte dos estudantes, até porque, a complexidade inerente ao modelo quântico pode contribuir para a diminuição do interesse dos estudantes.

LIVRO 4: MORRISON, R.T.; BOYD, R. N. Química Orgânica.13ª Edição. Lisboa: Ed. Fundação Calouste Gulbenkian, 1996.

O quarto livro analisado está organizado em três partes, divididas em 35 capítulos. Foram analisados o primeiro e o quarto capítulos, cujos títulos são respectivamente: Estrutura e Propriedades e Estereoquímica.

No início do primeiro capítulo há, em dois momentos, a tentativa dos autores em trazer alguma abordagem sobre o desenvolvimento histórico da Química Orgânica. No primeiro, o autor questiona o que teria o carbono de especial para formar tão elevado número de compostos. Como resposta, ele apresenta a seguinte citação de Kekulé:

Numa bela noite de verão, regressando eu a casa no último ônibus, na parte de cima como de costume, através das ruas desertas da grande metrópole (Londres), tão cheias de vida noutras horas, caí numa sonolência e zás!... os átomos saltitavam diante dos meus olhos... Vi como, frequentemente, dois átomos menores se uniam para formar um par, como um maior abraçava dois mais pequenos; como outros ainda maiores agarravam três ou mesmo quatro dos mais pequenos; entretanto o todo mantinha-se numa dança de roda. Vi como átomos maiores formavam uma cadeia... Passei parte da noite a desenhar no papel esboços destes sonhos (KEKULÉ apud MORRISON, 1996, p. 2). 
Num segundo momento, a segunda seção do primeiro capítulo do livro, intitulada: A Teoria Estrutural se inicia com uma angústia manifestada por Whöler:

\begin{abstract}
A Química Orgânica hoje em dia quase que me tira o juízo. Dá-me a impressão de uma floresta virgem tropical cheia de coisas extraordinárias, uma temerosa selva interminável, na qual não nos atrevemos a penetrar com receio de não encontrarmos a saída (WHÖLER apUd MORRISON, 1996, p. 3).
\end{abstract}

A citação é de 1835, e o autor do livro afirma em seguida que nos dias atuais existe um mapa para não nos perdemos na selva descrita por Whöler. Esse mapa seria a Teoria Estrutural. As duas citações acabam tendo apenas papel de anedota, uma vaga curiosidade, pois não há continuidade das discussões provocadas pelas citações; elas aparecem sem qualquer contexto e sem desenvolvimento dos trabalhos de Whöler.

Contudo, a passagem mais suscetível a crítica é a forma com que se inicia o terceiro subitem do primeiro capítulo, A ligação química antes de 1926, conforme abaixo:

Qualquer consideração sobre a estrutura das moléculas tem forçosamente que começar por uma análise das ligações químicas forças que mantêm os átomos unidos uns aos outros (MORRISON, 1996, p 4).

É necessário salientar aqui que van't Hoff e Le Bel propuseram independentemente, em 1874, a estrutura tetraédrica para compostos de carbono, mais de 40 anos antes da primeira teoria sobre ligações químicas. Então, será que realmente "qualquer consideração sobre a estrutura das moléculas tem forçosamente que começar por uma análise das ligações químicas"? A história diz que não, pois o que levou à proposta das estruturas tetraédricas de van't Hoff e Le Bel não foi o entendimento das ligações químicas, mas a compreensão sobre substâncias que possuíam as mesmas características físicas, porém desviavam a luz plano polarizada de maneira distinta, os chamados isômeros ópticos.

Pela forma como os autores apresentam os conceitos, entende-se que a abordagem deve ser iniciada discutindo-se ligações químicas, o que 
implica em considerar a existência de elétrons, já que a primeira proposta de ligação, feita por Lewis e Kossel, citados pelos próprios autores, é de 1916, e a descoberta do elétron se deu nos últimos anos do século XIX, logo, o trabalho de Kossel e Lewis já pressupõe a existência de elétrons.

Ainda no primeiro capítulo, na seção intitulada Orbitais hibridas: sp3 (o termo "hibridas" está no feminino pois a tradução do livro é portuguesa), os autores, utilizando o metano como exemplo, estabelecem que a geometria do carbono é tetraédrica, porque o carbono está hibridizado em sp3, admitindo que a geometria é consequência da hibridização e não que esta seja justificativa teórica daquela. Embora não seja possível apresentar uma citação que represente tal conclusão, a inversão da abordagem fica clara na leitura completa da seção.

Quando trata de estereoisomeria, no quarto capítulo, o livro traz uma abordagem muito interessante. Após os autores introduzirem o assunto no primeiro subitem, na segunda seção, que se intitula Número de isômeros. Carbono tetraédrico, é apresentada uma linha de raciocínio baseada nos trabalhos de van'† Hoff e Le Bel na qual se questiona o número de isômeros conhecidos para o metano monossubstituído.

Como nesse caso existe apenas um composto, os autores afirmam que seria possível existir para a molécula três formas capazes de explicar o dado empírico, (a) quadrado planar, com o átomo de carbono no centro de um quadrado e os demais átomos um em cada vértice; (b) piramidal de base quadrada, com o carbono no topo da pirâmide e quatro átomos em sua base; (c) tetraédrica, com o átomo de carbono no centro de um tetraedro e os demais átomos um em cada vértice.

As três formas citadas, e apenas elas, se adequam ao fato de existir apenas um composto de fórmula genérica $\mathrm{CH}_{3} \mathrm{X}$.

Ora, sabe-se também que existe apenas um composto de fórmula genérica $\mathrm{CH}_{2} \mathrm{XZ}$, quaisquer que sejam os átomos $\mathrm{X}$ e $\mathrm{Z}$, por exemplo, $\mathrm{CH}_{2} \mathrm{Cl}_{2}$ ou $\mathrm{CH}_{2} \mathrm{ClBr}$. Nesse caso apenas a estrutura tetraédrica é capaz de explicar esse resultado. Depois de apresentar essa discussão, os autores afirmam: 
Temos, pois, que só a estrutura tetraédrica do metano está de acordo com os resultados obtidos quanto ao número de isômeros. É certo que esse tipo de prova é de caráter negativo; poderia argumentar-se, efetivamente, ser possível existirem isômeros ainda não isolados ou detectados.... Há, todavia, outra prova, esta de caráter positivo, da estrutura tetraédrica do átomo de carbono: a descoberta precisamente da espécie de isômeros - enantiômeros que se preveem para os compostos de fórmula CWXY, através dessa estrutura. Foi a existência de enantiômeros que convenceu van'† Hoff e Le Bel de que o átomo de carbono era tetraédrico (MORRISON, 1996, p. 152).

Portanto, a abordagem desse livro, no que diz respeito aos compostos espacialmente arranjados, é mais adequada do ponto de vista de um referencial histórico. Embora os dados experimentais (trabalho de Pasteur) que desencadearam o trabalho de van't Hoff apareçam posteriormente na discussão, a abordagem é feita com aumento gradativo da complexidade, conforme defende Bachelard, pois retrata o contexto no qual van't Hoff desenvolveu seu trabalho, conhecendo os dados empíricos e, a partir deles, apresentou sua proposta.

A abordagem só não é mais adequada porque a separação enantiomérica executada com sucesso por Pasteur, que embasou experimentalmente os trabalhos posteriores, foi apresentada depois, caracterizando nesse caso uma inversão na sequência dos fatos.

Conclui-se que, dos livros analisados, é a obra de Morrison (1996) que apresenta, em pelo menos um aspecto, a abordagem mais coerente com o percurso histórico do tema analisado, tornando possível que o estudante compreenda que existe uma lógica intrínseca à proposta do carbono tetraédrico. Embora em outros aspectos o caminho traçado pelo autor seja idêntico aos demais livros analisados, pelo menos em um ponto este livro apresenta a discussão iniciando por questões mais simples para então inserir aspectos mais complexos.

A análise mostrou que os livros didáticos avaliados se iniciam com abordagens similares sobre estrutura e propriedades dos compostos orgânicos. Essa abordagem parte das características eletrônicas do átomo de carbono e de suas possibilidades de hibridação como origem da geometria das moléculas o contém. 
Embora os livros tragam algumas questões que remetem ao contexto histórico, o que aparece é apenas uma sucessão de fatos e datas, nem sempre na ordem em que ocorreram, enfocando principalmente a síntese da ureia como experimento crucial para mudança da forma de se compreender a Química Orgânica de "química de compostos presente em organismos vivos" para a "química do carbono".

Além da ausência do contexto histórico, no qual a disciplina foi construída, a crítica mais importante é sobre a ordem na qual os conceitos são introduzidos, pois os autores apresentam uma sequência contrária ao caminho histórico de construção do tema. Invariavelmente, eles iniciam com a apresentação do átomo de carbono, seus orbitais e configurações eletrônicas, ligações químicas e o tipo de hibridização que pode sofrer, para então apresentar as formas espaciais dos compostos orgânicos.

A proposição do carbono tetraédrico foi feita por van'† Hoff e Le Bel, isoladamente em 1876, e nesse momento histórico nem a existência de átomos era consenso entre químicos (existia uma controvérsia entre atomistas e equivalentistas). Além disso, a Teoria Quântica, que fundamenta as noções de orbitais atômicos e moleculares, surge só nos primeiros anos do século XX e mais, os modelos de ligação química que utilizam essa teoria como base foram desenvolvidos por Lewis na década de 1930, mais de meio século depois da interpretação geométrica dos compostos de carbono.

Portanto, a abordagem usualmente adotada pelos livros de Química Orgânica analisados inverte o caminho histórico trilhado pela ciência, fato que pode causar dificuldades para que o educando compreenda, por exemplo, que os modelos de ligações propostos são consequência da forma como os átomos se arranjam numa molécula e não o inverso.

Embora acreditemos que a utilização do contexto histórico como instrumento para o ensino de Química favoreça a aprendizagem, sabemos que outros caminhos também são possíveis. A discussão aqui levantada não tem por objetivo avaliar a existência ou não do contexto histórico coerente, amplo e bem fundamentado nos livros de Química Orgânica. Nosso objetivo foi avaliar, se a sequência de conceitos apresentados segue uma linha em 
que, o conhecimento tenha seu ponto de partida em aspectos mais empíricos e se desenvolva em direção ao abstrato, ao racional, baseado nas escolas filosóficas, nas quais Bachelard utilizou para propor as zonas do perfil epistemológico.

A insistência em recorrer ao contexto histórico nas discussões do presente capítulo são pertinentes, pois nos auxiliam a enquadrar cada conceito apresentado em sua respectiva zona do perfil epistemológico, usando como referencias as zonas que descrevemos, para a noção de estruturas dos compostos orgânicos.

Segundo nosso referencial epistemológico, podemos afirmar que os livros analisados não estão de acordo com a sequência na qual os conceitos deveriam ser apresentados, conforme discutido no decorrer das análises. Ressalvamos apenas um aspecto trazido por Morrison (1996), no qual o autor, baseado no trabalho de van't Hoff, apresenta, a partir dos dados teóricos conhecidos, como foi possível o químico holandês propor a geometria tetraédrica para o átomo de carbono.

Conforme discutimos, os livros apresentam as teorias vigentes, assim como era esperado. Porem nossa discussão com relação a abordagem dos livros, nos leva a afirmar que, para um educando conseguir compreender as discussões trazidas nos livros analisados, é necessário que ele tenha algum entendimento sobre os aspectos quânticos inerentes ao conhecimento químico, aspectos que enquadramos na quarta zona do perfil epistemológico. Essa compreensão seria facilitada, caso a abordagem fosse feita partindo de aspectos mais simples para culminar nos aspectos mais complexos como também já foi discutido, mas a escolha feita pelos autores dos livros analisados foi diferente.

\section{CONSIDERAÇÕES FINAIS}

Os livros didáticos, ao abordarem determinado assunto, necessariamente devem pressupor que para entender o conceito que será abordado, seus leitores tenham algum tipo de conhecimento prévio sobre o tema. Essa consideração não tem como ser dinamizada, pois os livros trazem 
a informação estática, ou seja, as informações ali contidas não podem mudar de acordo com as respostas dos leitores ou dificuldades que eles possam apresentar, como numa aula por exemplo. Por isso, os autores apresentam nos livros didáticos suas concepções a respeito da forma e da sequência na qual o assunto deva ser tratado. Com essa perspectiva, analisamos quais seriam os conceitos necessários, segundo a abordagem de cada um dos livros analisados, para que o leitor desses livros, pudesse compreender o conceito de estrutura dos compostos orgânicos e suas implicações para essa disciplina.

Notamos que todos os autores esperam que seus leitores, estudantes de Química Orgânica, tenham conhecimentos sobre as possibilidades de hibridização do átomo de carbono, como pressuposto inicial para as discussões relativas a estrutura espacial dos compostos orgânicos e a relação entre tal estrutura e as propriedades físicas e químicas destes compostos.

Embora as obras analisadas tenham sido escritas por autores estrangeiros (das cinco obras analisadas, quatro delas eram versões traduzidas, enquanto a quinta estava no seu idioma original) e, obviamente, a preocupação dos autores dessas obras certamente não é o acadêmico brasileiro, com base na literatura (BARKE; ENGIDA, 2001; MULLINS, 2008; ANDERSON; BODNER 2008; O'DWYER, 2012), podemos afirmar que as dificuldades apresentadas por acadêmicos de diversos países como Alemanha, Irlanda, Estados Unidos e Etiópia são similares às dificuldades apresentadas por alunos brasileiros (BELINASO et al, 2009; NASCIMENTO; BUENO FILHO, 2013; CEDRAN, 2015).

É interessante notar que, de maneira geral, todas as abordagens são similares. A ordem no qual os conceitos aparecem, os exemplos apresentados, os conceitos requeridos para o desenvolvimento do tema em estudo, não primam por muita variação ou criatividade. A diferença que se nota entre elas está na linguagem, algumas vezes mais rebuscada e em outros casos mais acessível, e também na tentativa de tornar o assunto mais interessante para o aluno. Por exemplo, enquanto um dos livros discute em 
seu inicio a formação das primeiras moléculas orgânicas no espaço para mostrar a origem dos compostos e sua importância em nosso cotidiano, outra obra, traz a "famosa" história da síntese da ureia, como experimento crucial que deu origem à Química Orgânica como subárea da Química. Entretanto, mesmo com diferentes introduções, quando os livros iniciam as discussões dos conceitos científicos, notamos mais uma vez a similaridade entre as obras.

Após entendermos quais são os requisitos necessários, segundo cada obra, para que fosse possível compreender o conceito químico que escolhemos investigar, passamos a refletir sobre como atrelar tal análise ao referencial epistemológico de Bachelard, especificamente com os perfis epistemológicos propostos. Sabemos que atribuir uma zona de perfil epistemológico para um livro talvez seja incoerente, justamente pelo caráter estático do livro e da necessidade de este apresentar as teorias vigentes, já que o livro didático não tem por objetivo apresentar minuciosamente a trajetória histórica dos conceitos científicos, mas sim, abordá-los de forma clara e acessível para que seu leitor possa compreendê-lo. É nesse sentido que se enquadra nossa análise, pois nosso objetivo, como já discutimos, foi avaliar quais conceitos seriam necessários para o educando compreender o que são, e qual a relevância, das estruturas dos compostos para o entendimento dos demais assuntos tratados na disciplina de Química Orgânica. Dessa forma, o enquadramento que propusemos em relação aos perfis epistemológicos apresentados foi dos conceitos químicos e não dos livros didáticos. Os ditos conceitos são os mínimos necessários para que um acadêmico possa compreender a abordagem do livro em análise, de acordo com nossa perspectiva. Por isso, concluímos que os autores das obras analisadas esperam que seus leitores possuam o perfil racionalista completo desenvolvido, já que nesse perfil enquadramos os conceitos relativos aos aspectos quânticos da compreensão da estrutura dos compostos, como a compreensão de orbitais híbridos por exemplo, assunto tratado no inicio das discussões apresentadas pelos livros didáticos. 
Mesmo que o objetivo não seja trazer o levantamento histórico dos conceitos, os livros apresentam nomes de cientistas e teorias por eles propostas para explicar determinados conceitos, por exemplo: o arranjo tetraédrico proposto por van'† Hoff; a tetravalência do carbono, bem como a possibilidade desse elemento formar cadeias, idealizada por Kekulé; e o trabalho de Pasteur que explica satisfatoriamente porque soluções de alguns compostos aparentemente idênticos têm comportamento diferente quando sobre eles incide um feixe de luz plano polarizada; entre outros.

Embora seja comum o aparecimento dos nomes teorias que citamos, a sequência na qual eles aparecem na maioria dos casos é diferente em relação a cronologia das contribuições desses personagens. Aqui tecemos nossa crítica: se os trabalhos desses cientistas são abordados pelos livros, porque não os trazer de forma que possa auxiliar na compreensão do conceito, fazendo com que o nível de entendimento inicial necessário do educando seja menor, discutindo as etapas da construção da ideia de estrutura dos compostos para então apresentar os conceitos derivados da teoria quântica cujo grau de complexidade é nitidamente maior. Repetimos o que já discutimos antes, mais grave que a inversão histórica, a nosso ver, é a inversão epistemológica que existe na sequência apresentada pelos livros didáticos, que apresentam conceitos mais complexos para, posteriormente apresentar noções mais simples.

\section{REFERÊNCIAS}

ALLINGER, N. L.; CAVA, M. P.; JONGH, D. C.; JOHNSON, C. R.; LEBEL, N. A.; STEVENS, C. L. Química Orgânica. Rio de Janeiro: LTC, 1976.

ANDERSON, T. L.; BODNER, G. M. What can we do about 'Parker'? A case study of a good student who didn't 'get' organic chemistry. Chemistry

Education Research and Practice. v. 9, p. $93-101.2008$.

ANDRADE, V. A.; ARAÚJO-JORGE, T. C.; SILVA, R. C. Perfil epistemológico do conceito sistema imune humano: delineamento e contribuições para o ensino de Imunologia. Latin American Journal of Science Education. v. 4, N. 1, p. 1 - 10. 2017.

BACHELARD, G. O Materialismo Racional. Lisboa: Edições 70, 1990. 
BACHELARD, G. A Filosofia do Não. Lisboa: Editorial Presença, 1991.

BACHELARD, G. A Formação do Espírito Científico, Rio de Janeiro, Editoria Contraponto, 1996.

BACHELARD, G. A Epistemologia, Lisboa, Edições 70, 2006.

BARKE, H. D.; ENGIDA, T. Structural Chemistry and Spatial Ability in Different Cultures. Chemistry Education: Research and Practice in Europe. v. 2, N. 3, p $227-239,2001$.

BELINASO, J., SILVA, S. M.; EICHLER, M. L.; SALGADO, T. D. M.; Del PINO, J. C.; Concepções de Estudantes Universitários Sobre os Conceitos Fundamentais de Química Orgânica. In: ENCONTRO NACIONAL DE PESQUISA EM

EDUCAÇÃO EM CIÊNCIAS, VII, Florianópolis, 2009. Anais Universidade Federal de Santa Caatarina, Florianópolis, 2013.

BRUICE, P. Y. Química Orgânica. São Paulo:Pearson, 2011.

BUSCATTI JUNIOR, D. A. O perfil epistemológico do conceito de espaço em alunos do curso de licenciatura em Física. 2014. Dissertação (Mestrado em Educação para a Ciência) - Universidade Estadual Paulista Júlio de Mesquita Filho, Bauru/SP, 2014.

\section{CAMEL, T. O. A Relevância das Teorias da Química Orgânica na Aceitação} do Conceito de Molécula e de uma Realidade Atômica. 2010. Tese

(Doutorado em História das Técnicas e Epistemologia) Universidade Federal do Rio de Janeiro, Rio de Janeiro/RJ, 2010.

CAMPANÁRIO, J. M.; Que puede hacer um professor como tu a un alumno como tuyo com um libro de texto como este? Una relación de actividades poco convencionales. Enseñanza de las Ciencias, v. 19, n. 3, p 351-364, 2001.

CEDRAN, J. C. O conceito de estrutura dos compostos orgânicos: uma análise à luz da Epistemologia de Gaston Bachelard. 2015. Tese (Doutorado em Educação para a Ciência e a Matemática). Universidade Estadual de Maringá, Maringá/PR, 2015.

FERNANDES, M. A. M.; PORTO, P. A., Investigando a presença da história da ciência em livros didáticos de Química Geral para o ensino superior. Química Nova, v. 35, n. 2, p. 420-429, 2012.

KEKULÉ, A. Lehrbuch der Organischen Chemie. verlag von Ferdinad Enke, Erlangen, 1861.

MORRISON, R.T.; BOYD, R. N. Química Orgânica. Lisboa: Fundação Calouste Gulbenkian, 1996. 
MORTIMER, E. F. Para Além das Fronteiras da Química: Relações Entre Filosofia, Psicologia e Enisno de Química. Química Nova. v. 20, N.2, p.200-207, 1997

MULLINS, J.J. Six Pillars of Organic Chemistry. Journal of Chemical Education, $v$. 85, n. 1, p. $83-87.2008$.

NASCIMENTO, G. M.; BUENO FILHO, M. A. Elementos Estruturadores da Química Orgânica Implícitos na Argumentação de Professores e Alunos de Graduação. In: CONGRESO INTERNACIONAL SOBRE INVESTIGACIÓN EN DIDÁCTICA DE LAS CIENCIAS, IX, Giona. 2013. Anais Girona-Espanha, 2013.

O'DWYER, A. Identifications of Difficulties in Teaching and Learning of Introductory Organic Chemistry in Ireland and the Development of a SecondLevel Intervention Program. 2012. Tese (Doutorado em Filosofia) Universidade de Limerick, Limerick (Irlanda), 2012.

PASTEUR, L. The Asymmetry of Naturally Occurring Organic Compounds. In: RICHARDSON, G. M. (Org) Foundations of Stereo Chemistry. New York: American Book Company, 1901. p $3-17$.

SOLOMOS, G.; FRYHLE, C. Química Orgânica.Vol. 1. Rio de Janeiro: LTC, 2000.

SOUZA, P. H. Tempo, Ciência, História e Educação: Um diálogo entre a

Cultura e o Perfil Epistemológico. 2008. Tese (Doutorado em Educação) Universidade de São Paulo, São Paulo/SP, 2008.

SOUZA, P. H.; ZANETIC, J. SANTOS, M. E. Conceito de Espaço no Ensino de Física: Construindo Categorias de Análise à luz da Epistemologia de Bachelard. In: ENCONTRO NACIONAL DE PESQUISA EM EDUCAÇÃO EM CIÊNCIA, VIII, 2011 Campinas. Anais... Campinas: Universidade Estadual de Campinas, 2009.

SOUZA FILHO, M. P. O Erro em Sala de Aula: Subsídios para o Ensino do Eletromagnetismo. 2009. Tese (Doutorado em Ensino de Ciências) Universidade Estadual Paulista, Bauru/SP, 2009.

VAN'T HOFF, J. H. Sur Les Formules de Structure dans L'espace. Archives néerlandaises des sciences exactes et naturelles. v. 9, p. 445 - 454, 1874.

Recebido em: 17 de julho de 2018 Aprovado em: 15 de maio de 2019 